\title{
Adaptive memory: The survival-processing memory advantage is not due to negativity or mortality salience
}

\author{
Raoul Bell • Jan P. Röer • Axel Buchner
}

Published online: 11 January 2013

(C) Psychonomic Society, Inc. 2013

\begin{abstract}
Recent research has highlighted the adaptive function of memory by showing that imagining being stranded in the grasslands without any survival material and rating words according to their survival value in this situation leads to exceptionally good memory for these words. Studies examining the role of emotions in causing the survival-processing memory advantage have been inconclusive, but some studies have suggested that the effect might be due to negativity or mortality salience. In Experiments 1 and 2, we compared the survival scenario to a control scenario that implied imagining a hopeless situation (floating in outer space with dwindling oxygen supplies) in which only suicide can avoid the agony of choking to death. Although this scenario was perceived as being more negative than the survival scenario, the survivalprocessing memory advantage persisted. In Experiment 3, thinking about the relevance of words for survival led to better memory for these words than did thinking about the relevance of words for death. This survival advantage was found for concrete, but not for abstract, words. The latter finding is consistent with the assumption that the survival instructions encourage participants to think about many different potential uses of items to aid survival, which may be a particularly efficient form of elaborate encoding. Together, the results suggest that thinking about death is much less effective in promoting recall than is thinking about survival. Therefore, the survival-processing memory advantage cannot be satisfactorily explained by negativity or mortality salience.
\end{abstract}

R. Bell $(\bowtie) \cdot$ J. P. Röer · A. Buchner

Department of Experimental Psychology, Institut für

Experimentelle Psychologie, Heinrich-Heine-Universität

Düsseldorf, 40225 Düsseldorf, Germany

e-mail: raoul.bell@hhu.de
Keywords Survival-processing effect - Negativity effect . Emotional memory enhancement $\cdot$ Mortality salience . Evolution

It follows from an evolutionary perspective on cognition that a complete understanding of memory would require an analysis of the selection pressures that might have shaped memory functions during evolution (Klein, Cosmides, Tooby, \& Chance, 2002; Nairne, 2010; Nairne \& Pandeirada, 2010). Consistent with evolutionarily inspired hypotheses, material that is relevant for specific adaptive ends such as mating (Allan, Jones, DeBruine, \& Smith, 2012), foraging for food (New, Krasnow, Truxaw, \& Gaulin, 2007), threat avoidance (Wilson, Darling, \& Sykes, 2011), and reciprocal altruism (Bell, Buchner, \& Musch, 2010; Buchner, Bell, Mehl, \& Musch, 2009) is particularly well remembered. A recurring issue of controversy is whether these phenomena can only be adequately explained by highly specialized evolutionary modules, or whether they can be resolved by general memory principles (e.g., Bell \& Buchner, 2012).

The debate was fueled by the observation that memory for material processed under a survival perspective is exceptionally good (Nairne \& Pandeirada, 2008a; Nairne, Pandeirada, \& Thompson, 2008; Nairne, Thompson, \& Pandeirada, 2007), which could be interpreted as evidence for an immediate influence of selection factors on human memory (Nairne, 2010; Nairne \& Pandeirada, 2008b). In the survival-processing paradigm, participants are required to imagine that they are stranded in the grasslands of a foreign land without any survival materials, deprived of food and water, and in danger of predators. Then a list of items is presented that the participants are asked to rate one at a time, according to how relevant or useful these items would be in this situation. After the rating task, a surprise memory test follows in which the participants are asked to write down all of the items that they can recall. These encoding instructions 
lead to a recall advantage in comparison to different types of encoding procedures that emphasize "deep" processing (Craik \& Lockhart, 1972), such as imagery, generation, intentional learning, or rating words according to their self-relevance, which are typically associated with exceptionally good memory performance (Nairne et al., 2008). To control for schematic processing, the survival condition is often compared to conditions in which participants are required to rate the words according to their relevance for another scenario, such as moving to a foreign land (Nairne et al., 2007). The survival-processing memory advantage has been replicated with different control conditions (Weinstein, Bugg, \& Roediger, 2008), stimulus materials (Otgaar, Smeets, \& van Bergen, 2010), encoding tasks (Röer, Bell, \& Buchner, in press), and populations (Aslan \& Bäuml, 2012).

While the memory benefit itself has been demonstrated numerous times, the mechanisms underlying the recall advantage have remained unclear. From an evolutionary perspective, one might assume that the human mind comprises highly specialized adaptations serving to enhance memory for fitness-relevant material (Nairne et al., 2007). However, even if one accepts evolutionary adaptation as the ultimate explanation of the survival-processing effect, the question arises of which proximate mechanisms underlie the memory advantage. Several promising candidate mechanisms have been identified (see also Howe \& Otgaar, in press).

Erdfelder and Kroneisen (in press) distinguished between cognitive and emotional explanations. Cognitive explanations imply that the survival memory advantage can be ascribed to an efficient form of encoding, representation, or retrieval that is generally associated with good memory. For instance, Burns, Burns, and Hwang (2011) proposed that survival processing fosters both relational and itemspecific processing at encoding, and that it is therefore superior to control strategies, which rely either only on relational or only on item-specific processing. Klein, Robertson, and Delton (2011) suggested that planning for the future is an important component of the survivalprocessing effect. Butler, Kang, and Roediger (2009) showed that the survival-processing effect is moderated by the fit between the to-be recalled material and the scenarios used. However, the survival-processing memory advantage persists when relevance of the materials for each scenario is controlled for (Nairne \& Pandeirada, 2011).

While there is evidence that visual imagery contributes little to the survival-processing effect (Kroneisen, Erdfelder, \& Buchner, in press), richness of encoding seems to be a potentially important proximate mechanism (Kroneisen \& Erdfelder, 2011; Kroneisen et al., in press; Röer et al., in press). Kroneisen and Erdfelder proposed that survivalprocessing instructions stimulate thinking about different uses of the items that may aid survival in the grassland scenario. This elaborate form of encoding could lead to better recall, because the elaborations that are still available at test could be used as cues to retrieve or infer the to-be recalled words (Anderson, 1983). Consistent with this approach, it has been observed that participants spontaneously generate more uses for items in the survival scenario than in control scenarios (Röer et al., in press). When the possibility to generate different ideas is limited, the survival-processing advantage is abolished (Kroneisen \& Erdfelder, 2011; Kroneisen et al., in press). Thus, it seems probable that the survival-processing memory advantage is mediated by thoughts about possible uses of objects in the survival scenario.

Emotional explanations of the survival-processing memory advantage ascribe the phenomenon to beneficial effects of emotion on memory. Given that survival-relevant stimuli are often associated with strong emotional reactions, it is possible to speculate that emotions may determine the memory effect. It is well known - both from everyday experience and from scientific evidence - that emotions have a powerful impact on memory. A large body of research has shown that negative emotions can enhance recollection (Kensinger, 2007; Kensinger \& Corkin, 2003). However, the relationship between emotion and memory is complex. Emotionally neutral information that is presented in a highly emotional context is often remembered poorly, probably because attention is drawn to those stimuli that are central to the emotional experience, and away from nonemotional aspects of the encoding episode (Kensinger, Garoff-Eaton, \& Schacter, 2007; Levine \& Edelstein, 2009; Mather, 2007). Therefore, it remains unclear whether the encoding of neutral words benefits from a highly emotional encoding scenario. Given this lack of clarity, it seems interesting to examine the role of emotions in the survival-processing paradigm.

The literature on the role of emotions in the survivalprocessing paradigm (Hart \& Burns, 2012; Kang, McDermott, \& Cohen, 2008; Smeets, Otgaar, Raymaekers, Peters, \& Merckelbach, 2012; Soderstrom \& McCabe, 2011) does not lead to a clear conclusion. Kang et al. compared the survival scenario to a bank heist scenario in which participants were asked to imagine that they were planning to rob a bank. Recall in the survival condition exceeded recall in the bank heist condition, although both scenarios received similar excitement ratings in a norming study. However, given that valence ratings were not obtained, the study leaves open the possibility that the survival-processing advantage is caused by a negativity effect. Smeets et al. speculated that the survival-processing scenario may induce stress, which may improve memory via the effects of stress hormones. However, the beneficial effects of stress on memory were found to be independent of the survivalprocessing effect. The study of Soderstrom and McCabe, in contrast, seems to provide clear evidence for the influence of 
emotions, at least at first sight. They found that imagining having to protect oneself from zombies led to even better recall than the original grasslands survival scenario. Given that the zombie survival scenario was more negative and more arousing than the grasslands survival scenario, it seems plausible to assume that recall improves as a function of the emotional characteristics of the scenarios. However, the arousal and valence judgments could not fully account for the memory advantage. Hart and Burns showed that thinking about one's own death prior to encoding had beneficial effects on recall and speculated that the survival-processing advantage may be explained by the effects of mortality salience on memory. However, the effects of mortality salience and survival processing were not compared directly in that study.

Most situations that stimulate thinking about one's own death are also highly survival relevant. The same is true for situations that induce strong negative emotions in general. Therefore, it is exceedingly difficult to disentangle the contributions of these types of processes to the survivalprocessing effect. The aim of the present series of experiments was to test whether negativity and mortality salience are sufficient for obtaining a survival-processing advantage, or whether it is necessary that the rating task encourages participants to think about the fitness-enhancing effects of the words. In Experiments 1 and 2, we compared the grasslands survival scenario to a control scenario in which participants were required to imagine themselves in a hopeless situation (floating in outer space with dwindling oxygen supplies) in which they decided to end their life (see Table 1). This scenario was perceived as being even more negative than the grasslands survival scenario, and it is plausible to assume that it induced mortality salience more directly. In Experiment 3, judging the relevance of words for survival was compared to judging the relevance of words for death. If the survival-processing advantage were due to negativity or mortality salience, recall in these control conditions should exceed recall in the survival condition. However, if thinking about the fitness-enhancing effects of items is a necessary component of survival processing, a recall advantage should be restricted to those conditions that induce a survival focus at encoding. Therefore, recall in the survival conditions should exceed recall in the control conditions.

\section{Experiment 1}

\section{Method}

Ethics statement The study was approved by the ethics committee of the Medical Faculty at Heinrich Heine University Düsseldorf. The participants signed informed consent before starting the experiment.
Participants The participants were 84 students (49 women, 35 men). Their ages ranged from 18 to 47 years $(M=25.42$, $S D=5.68$ ). The data from one outlier were eliminated because the experimenter noted that the participant did not follow the instructions. Eliminating this person did not change the statistical conclusions.

Materials The same word list was used as in Nairne et al.'s (2007) Experiments 1-2 (after translation into German). The written instructions are summarized in Table 1. Valence and exceptionality ratings for the scenarios were assessed in an independent norming study $(N=71)$. Table 2 shows that the survival scenario was more negative than the moving scenario, $t(70)=-9.8, p<.01, \eta^{2}=.58$, which has served as the standard control scenario in most studies examining the survival-processing advantage. However, the suicide scenario was even more negative than the survival scenario, $t(70)=-9.5, p<.01, \eta^{2}=.56$. Furthermore, the survival scenario was more exceptional than the moving scenario, $t(70)=7.8, p<.01, \eta^{2}=.47$, but the suicide scenario was even more exceptional, $t(70)=-4.2, p<.01, \eta^{2}=.20$.

Procedure Participants were randomly assigned to four groups that received different instructions for the rating task (see Table 1); they were asked to rate how useful the items were for survival, suicide, or moving, or they were asked to rate the items' pleasantness. The words were presented in a random order. Each word stayed on the computer screen for $5 \mathrm{~s}$, during which it was rated on a scale ranging from 1 (completely useless/very unpleasant) to 5 (very useful/very pleasant). After a blank 1-s intertrial interval, the next word was shown.

After the rating phase, participants completed eight trials of a distractor task in which they were required to serially recall eight digits in silence. The serial recall task was identical to the one used in a recent working memory study (Röer, Bell, Dentale, \& Buchner, 2011). Serial recall did not differ among the conditions $[F(3,80)=0.15, p=.93$, $\left.\eta^{2}=.01\right]$. Subsequently, participants received a blank sheet of paper and a pen and were asked to write down as many words from the rating phase as they could recall, regardless of the order of their presentation. A maximum of $10 \mathrm{~min}$ was given to complete the recall task.

Design A between-subjects design was used, with rating task (survival vs. suicide vs. moving vs. pleasantness) as the independent variable. The dependent variable was free recall performance (i.e., the proportion of words correctly remembered). A sensitivity analysis suggested that given a sample size of $N=84$ and $\alpha=.05$, an effect of size $f=0.46$ could be detected with a probability of $1-\beta=.95$ among the four levels of the rating task variable. All other things being equal, effects of size $f=0.46,0.49$, and 0.57 could be detected for, respectively, the comparison between the 
Table 1 Instructions for the rating tasks used in Experiments 1, 2, and 3

\begin{tabular}{|c|c|}
\hline Condition & Instructions \\
\hline \multicolumn{2}{|c|}{ Experiments 1 and 2} \\
\hline Survival & $\begin{array}{l}\text { Imagine yourself being stranded in the grasslands of a foreign land. In the near future you have to take care of getting food and } \\
\text { water, and you have to protect yourself from predators. What could help you to achieve this goal? We are going to show you a } \\
\text { list of } 30 \text { items. Please rate how useful these items are in your situation. }\end{array}$ \\
\hline Suicide & $\begin{array}{l}\text { Imagine yourself being in a space capsule, and your supply of oxygen is dwindling. There is no hope for rescue, and to avoid the } \\
\text { agony of choking to death, you decide to take your own life. What could help you to achieve this goal? We are going to show } \\
\text { you a list of } 30 \text { items. Please rate how useful these items are in your situation. }\end{array}$ \\
\hline Moving & $\begin{array}{l}\text { Imagine yourself planning to move to a foreign country in the near future. You have to find a suitable new home, and you have to } \\
\text { transport your belongings. What could help you to achieve this goal? We are going to show you a list of } 30 \text { items. Please rate } \\
\text { how useful these items are in your situation. }\end{array}$ \\
\hline Pleasantness & We are going to show you a list of 30 items. Please rate how pleasant you find these items. \\
\hline \multicolumn{2}{|l|}{ Experiment 3} \\
\hline Survival & $\begin{array}{l}\text { We are going to show you a list of words, one after another. These words are more or less relevant for survival. Your task is to } \\
\text { judge the relevance of these words with respect to survival. How relevant are these words for survival? }\end{array}$ \\
\hline Death & $\begin{array}{l}\text { We are going to show you a list of words, one after another. These words are more or less relevant for death. Your task is to judge } \\
\text { the relevance of these words with respect to death. How relevant are these words for death? }\end{array}$ \\
\hline
\end{tabular}

survival-rating task and all of the other rating tasks combined, the comparison between the suicide-rating task and the moving- and pleasantness-rating tasks combined, and the comparison between the moving- and the pleasantnessrating tasks. The power calculation was conducted using G*Power (Faul, Erdfelder, Lang, \& Buchner, 2007).

\section{Results}

Encoding-phase ratings Table 3 shows that the mean usefulness ratings differed among the rating tasks, $F(3,80)=$ $54.15, p<.01, \eta^{2}=.67$ : They were higher in the survival than in the moving condition, $t(39)=4.42, p<.01, \eta^{2}=.33$, and higher in the moving than in the suicide condition, $t(41)=4.04, p<.01, \eta^{2}=.28$.

Recall At a descriptive level, recall performance was better in the survival condition than in all of the other conditions, including the suicide condition (see Fig. 1). An analysis of variance (ANOVA) confirmed that the rating task significantly

Table 2 Valence and exceptionality ratings of the scenarios, obtained in an independent norming study

\begin{tabular}{|c|c|c|c|c|c|c|}
\hline & \multicolumn{2}{|c|}{ Survival } & \multicolumn{2}{|c|}{ Suicide } & \multicolumn{2}{|c|}{ Moving } \\
\hline & $M$ & $S D$ & $M$ & $S D$ & $M$ & $S D$ \\
\hline Valence & -1.5 & 1.8 & -3.5 & 0.8 & 1.2 & 2.2 \\
\hline Exceptionality & 5.8 & 2.0 & 6.8 & 1.8 & 3.4 & 2.3 \\
\hline
\end{tabular}

Valence was assessed using a scale ranging from -4 (very negative) to +4 (very positive). Exceptionality was assessed on a scale ranging from 0 (very ordinary) to 8 (very exceptional) affected recall, $F(3,80)=4.84, p<.01, \eta^{2}=.15$. Orthogonal contrasts showed that survival rating led, in fact, to better recall than did all of the other rating tasks combined, $F(1,82)=12.50$, $p<.01, \eta^{2}=.13$, confirming the survival-processing recall advantage for the present experiment, as well as that the suicide condition did not differ significantly from the two other control conditions (moving and pleasantness), $F(1,82)=0.97, p=.33$, $\eta^{2}=.01$, which in turn did not differ significantly from each other, $F(1,82)=0.98, p=.33, \eta^{2}=.01$.

Survival processing tends to yield higher probabilities of false memories than do control scenarios (Howe \& Derbish, 2010; Otgaar \& Smeets, 2010). Therefore, it seemed interesting to analyze the number of intrusion errors, which, however, did not differ among the rating tasks, $F(3,80)=$ $1.23, p=.31, \eta^{2}=.04$ (see Table 3$)$.

\section{Discussion}

In Experiment 1, the typical survival-processing advantage was obtained. In contrast, the suicide-rating task did not lead to a recall advantage over the control conditions. This pattern of results suggests that the survival-processing effect cannot be explained by negativity or mortality salience. Instead, the stimulation of thoughts about the fitness-enhancing effects of items seems to be necessary for obtaining a recall advantage.

In Experiment 2, we examined the influence of task congruity by manipulating the task relevance of the items. Three types of items were presented: the words that people generated most often when asked to think about useful items in either a survival or a suicide condition, as well as items that were equally irrelevant in both scenarios. Despite a comparably large sample of 84 participants, we were only able to draw conclusions about large effects in Experiment 
Table 3 Mean usefulness/pleasantness ratings and mean numbers of intrusion errors as a function of scenario (Exp. 1)

\begin{tabular}{|c|c|c|c|c|c|c|c|c|}
\hline & \multicolumn{2}{|c|}{ Survival } & \multicolumn{2}{|c|}{ Suicide } & \multicolumn{2}{|c|}{ Moving } & \multicolumn{2}{|c|}{ Pleasantness } \\
\hline & $M$ & $S D$ & $M$ & $S D$ & $M$ & $S D$ & $M$ & $S D$ \\
\hline Usefulness/pleasantness ratings & 3.1 & 0.3 & 2.0 & 0.4 & 2.5 & 0.4 & 3.5 & 0.4 \\
\hline Intrusion errors & 1.1 & 0.8 & 1.4 & 1.2 & 1.7 & 1.6 & 1.1 & 1.2 \\
\hline
\end{tabular}

1, due to the between-subjects design. In Experiment 2, a within-subjects manipulation of the rating task variable was used to increase the sensitivity of our statistical comparisons. The hypotheses were identical to those of Experiment 1. If the survival-processing advantage were due to either negativity or mortality salience, we would expect suicide processing to lead to better recall than would survival processing. However, if the stimulation of thoughts about the fitness-enhancing effects of items is necessary for obtaining a recall advantage, survival processing should lead to better recall than would suicide processing.

\section{Experiment 2}

\section{Method}

Participants The participants were 114 students (83 women, $31 \mathrm{men})$. Their ages ranged from 18 to 58 years $(M=24.82, S D=5.82)$.

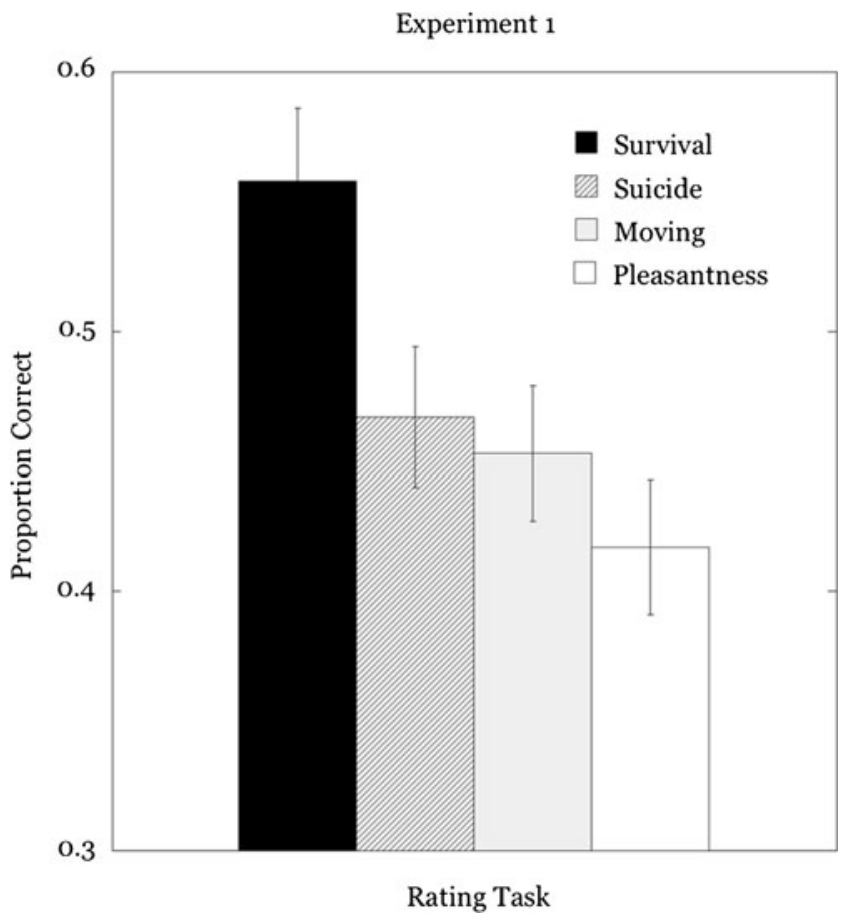

Fig. 1 Average proportions of correctly recalled words as a function of rating task (survival vs. suicide vs. moving vs. pleasantness) in Experiment 1 . The error bars represent the standard errors of the means
Materials Again, we compared the survival-rating task with the suicide-rating task. As a control condition, the pleasantness-rating condition was used. To obtain items that were relevant for either the survival or the suicide scenario, we asked each of 22 participants in an independent norming study ( $n=11$ in each group) to write down 30 items that could be of help in the survival scenario, and 30 items that could be of help in the suicide scenario. Of the most frequently generated items, 45 in each condition were then selected for the experiment proper. The properties of these items are documented in Table 4 . We also used 45 irrelevant items that were deliberately selected to be equally irrelevant in both scenarios. The complete set of items is given in Appendix A.

Procedure The procedure was identical to that of Experiment 1, with the following exceptions. First, rating task (survival, suicide, or pleasantness) was manipulated within subjects: The rating tasks were blocked, and the presentation order of the rating tasks was counterbalanced across participants. The instructions of the rating tasks were presented visually and auditorily before each block. In a given rating task block, participants saw a randomly selected set of 15 survival-relevant words, 15 suicide-relevant words, and 15 irrelevant words. These words were randomly selected without replacement from the pool of 45 survival-relevant, 45 suicide-relevant, and 45 irrelevant words. At the end of the experiment, participants were required to write down the words in a surprise free recall test, which lasted for $10 \mathrm{~min}$.

Table 4 Numbers of times that items were generated in response to the survival scenario and the suicide scenario in an independent norming study, along with mean frequency per million according to the CELEX database, mean numbers of syllables, and mean numbers of letters, averaged across the items

\begin{tabular}{lccc}
\hline & $\begin{array}{c}\text { Survival- } \\
\text { Relevant }\end{array}$ & $\begin{array}{l}\text { Suicide- } \\
\text { Relevant }\end{array}$ & Irrelevant \\
\hline $\begin{array}{l}\text { Number of times generated } \\
\text { in the survival scenario }\end{array}$ & 3.9 & 0.4 & 0.0 \\
$\begin{array}{l}\text { Number of times generated } \\
\text { in the suicide scenario }\end{array}$ & 0.4 & 3.8 & 0.0 \\
Frequency per million & 12.5 & 10.5 & 11.5 \\
$\begin{array}{l}\text { Number of syllables } \\
\text { Number of letters }\end{array}$ & 2.1 & 2.4 & 2.1 \\
\hline
\end{tabular}


Design A $3 \times 3$ design was used, with rating task (survival, suicide, and pleasantness) and item type (survival-relevant, suicide-relevant, and irrelevant) as within-subjects independent variables. The dependent variables were the encodingphase ratings and the recall performance. Given a total sample size of $N=114, \alpha=.05$, and the assumption that the average population correlation between the levels of the repeated measures factor was $\rho=.5$, an effect of size $f=0.15$ could be detected with a probability of $1-\beta=.95$.

Results

Encoding-phase ratings The usefulness ratings are shown in Table 5. The survival-relevant items were rated as being more useful in the survival scenario than in the suicide scenario, $t(113)=18.37, p<.01, \eta^{2}=.76$. In contrast, the suicide-relevant items were perceived as being more useful in the suicide scenario than in the survival scenario, $t(113)=9.07, p<.01, \eta^{2}=.42$, as expected. The irrelevant items were perceived as being equally irrelevant in both scenarios, $t(113)=1.04, p=.30, \eta^{2}=.01$. Interestingly, the survival-relevant items received more positive pleasantness ratings than did the irrelevant items, $t(113)=$ $5.83, p<.01, \eta^{2}=.23$, and the suicide-relevant items were perceived as being more negative than the irrelevant items, $t$ $(113)=-11.77, p<.01, \eta^{2}=.55$.

Recall Replicating Experiment 1, we found a significant effect of rating task on recall, $F(2,112)=22.95, p<.01$, $\eta^{2}=.29$. Averaged across all items, survival processing led to better recall than did suicide processing, $t(113)=3.73, p$ $<.01, \eta^{2}=.11$, which in turn led to better recall than did rating the items for pleasantness, $t(113)=4.12 p<.01, \eta^{2}=$ .13 (see the upper panel of Fig. 2). We also found an effect of item type, $F(2,112)=302.51, p<.01, \eta^{2}=.84$, in which suicide-relevant words were generally remembered better than survival-relevant words, which were in turn were remembered better than irrelevant words, as well as a significant interaction between the two variables, $F(4,110)=$ 13.65, $p<.01, \eta^{2}=.33$.

Table 5 Mean usefulness and pleasantness ratings as a function of scenario and item type (Exp. 2)

\begin{tabular}{|c|c|c|c|c|c|c|}
\hline \multirow[b]{3}{*}{ Item Type } & \multicolumn{4}{|c|}{ Usefulness Ratings } & \multicolumn{2}{|c|}{ Pleasantness Ratings } \\
\hline & \multicolumn{2}{|c|}{ Survival } & \multicolumn{2}{|c|}{ Suicide } & & \\
\hline & $M$ & $S D$ & $M$ & $S D$ & $M$ & $S D$ \\
\hline Survival-relevant & 4.0 & 0.6 & 2.5 & 0.6 & 3.4 & 0.4 \\
\hline Suicide-relevant & 3.3 & 0.6 & 4.0 & 0.6 & 2.4 & 0.5 \\
\hline Irrelevant & 1.5 & 0.4 & 1.4 & 0.4 & 3.1 & 0.3 \\
\hline
\end{tabular}

In the lower panel of Fig. 2, recall performance is shown as a function of item type and rating task. For survival-relevant items, a pronounced recall advantage is apparent for the survival-rating task over the suicide-rating task, $t(113)=$ $5.86, p<.01, \eta^{2}=.23$, which in turn led to better recall than did the pleasantness-rating task, $t(113)=2.80, p<.01$, $\eta^{2}=.06$. For suicide-relevant items, recall did not differ between the survival condition and the suicide condition, $t$ $(113)=-0.58, p=.57, \eta^{2}<.01$. However, recall in both the survival- and suicide-rating conditions was better than recall in the pleasantness condition, $t(113)=3.90, p<.01, \eta^{2}=.12$, and $t(113)=4.66, p<.01, \eta^{2}=.16$, respectively. For the irrelevant words, the descriptive advantage of the survival
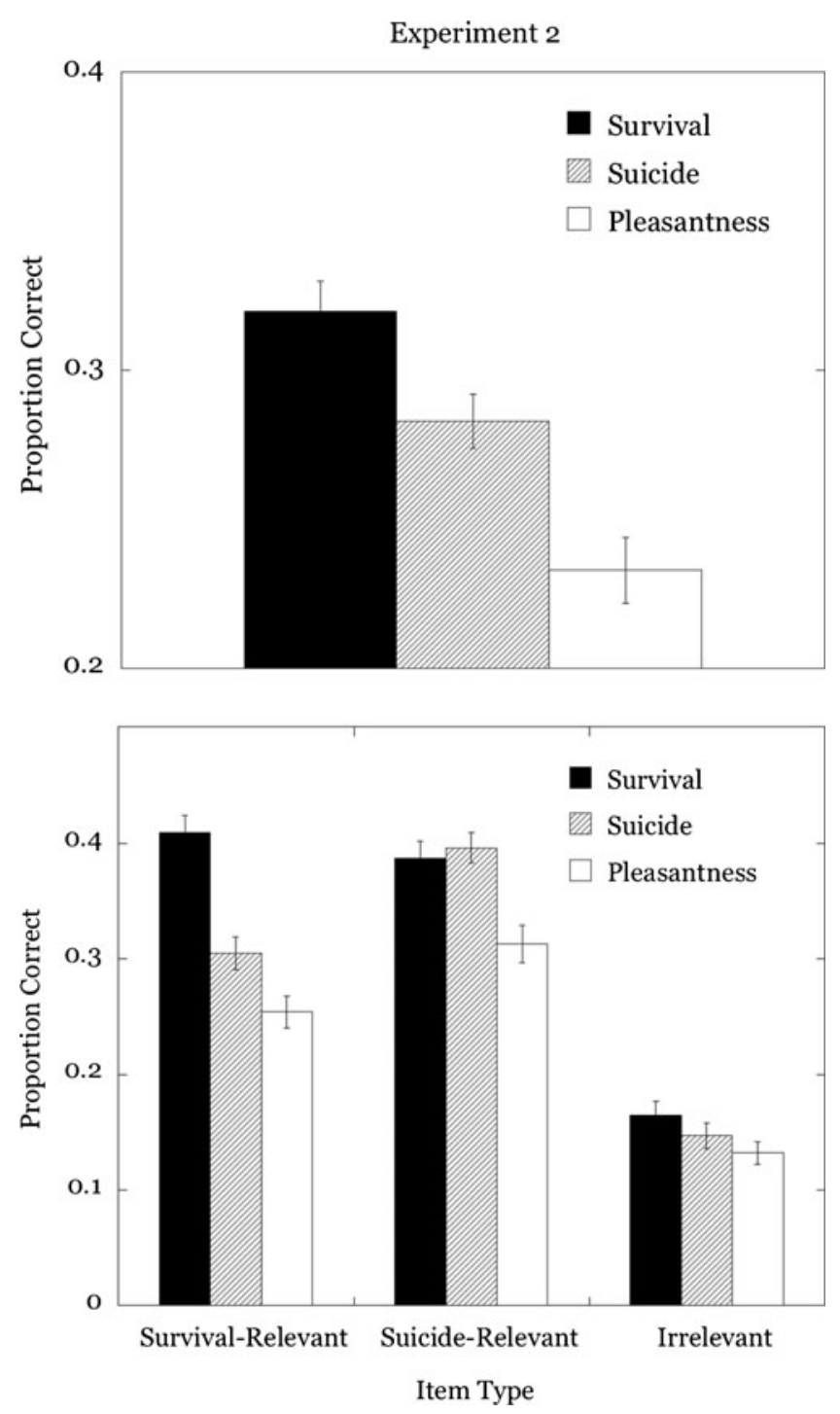

Fig. 2 (Upper panel) Average proportions of correctly recalled words as a function of scenario (survival vs. suicide vs. pleasantness), averaged across all items. (Lower panel) Average proportions of correctly recalled words as a function of scenario and item type (survivalrelevant vs. suicide-relevant vs. irrelevant) in Experiment 2. The error bars represent the standard errors of the means 
condition in comparison to the suicide condition missed significance, $t(133)=1.26, p=.21, \eta^{2}=.01$, but there was a recall advantage for the survival-rating task in comparison to the pleasantness-rating task $t(133)=2.06, p<.05, \eta^{2}=.04$. In contrast, the difference between the suicide-rating task and the pleasantness-rating task did not reach statistical significance, $t(133)=0.98, p=.33, \eta^{2}=.01$.

\section{Discussion}

Consistent with previous findings (Butler et al., 2009; Nairne \& Pandeirada, 2011), congruity had an effect on memory performance. However, this congruity effect was asymmetric. For survival-relevant words, a clear memory advantage emerged for the survival-rating task in comparison to the suicide-rating task. For suiciderelevant words, we found no difference between the survival and suicide conditions, even though the words were more relevant for the suicide scenario than for the survival scenario, and even though the suicide scenario was more negative than the survival scenario. For the irrelevant words, an advantage was found for the survival condition in comparison to the pleasantness condition, but no advantage of the suicide condition over the pleasantness condition. Averaged across all items, recall following the survival-rating task was clearly superior to recall following the suicide-rating task. In contrast to Experiment 1, the suicide-rating task led to better recall than did the pleasantness-rating task, but note that this finding may be at least partly due to the congruency effect.

Taken together, the results of Experiment 2 confirmed those of Experiment 1. Given that the suicide scenario led to worse recall despite being more negative than the survival scenario, the memory advantage cannot be due to the negativity of the stimulus materials. A theoretical view that attributes the survival-processing memory advantage to beneficial effects of negativity on memory would lead to the hypothesis that a control scenario that is more negative than the survival scenario would lead to better memory performance than the survival scenario. However, the results of Experiments 1 and 2 do not indicate a strong direct relationship between the negativity of the encoding scenario and recall performance.

However, although the tasks used above had a high degree of face validity, it could be argued that it remains unclear to what degree the different rating tasks might stimulate thoughts about survival and death. Therefore, in Experiment 3 we decided to use the most direct manipulation of survival processing versus death processing that is conceivable: Participants were simply asked to judge a list of items according to either their relevance for survival or their relevance for death. If the survival advantage is due to the induction of mortality salience, the survival-rating task should lead to worse memory performance than the deathrating task. If, in contrast, a survival focus is a necessary component of the memory advantage, the survival-rating task should lead to better memory performance than does the death-rating task.

In addition, we manipulated the concreteness of the words in Experiment 3. This manipulation seemed interesting in the context of the richness-of-encoding account of the survival-processing memory advantage (Kroneisen \& Erdfelder, 2011). Richness of encoding is a broad concept, but discussion of it often focuses on thoughts about the possible uses of objects in the survival scenario (Erdfelder \& Kroneisen, in press; Kroneisen \& Erdfelder, 2011; Kroneisen et al., in press; Röer et al., in press). For instance, Kroneisen and Erdfelder suggested that the survivalprocessing instructions stimulate a particularly effective form of elaborate encoding because "many possible uses of the objects indicated by the words come to mind, enhancing what we call the pragmatic distinctiveness of the words" (p. 1554). If the effect is indeed due to the stimulation of thoughts about the possible uses of objects that might help survival, the effect should be much more pronounced for concrete words denoting real objects than for abstract words.

\section{Experiment 3}

\section{Method}

Participants The participants were 89 students ( 75 women, 14 men). Their ages ranged from 18 to 37 years $(M=21.97$, $S D=3.69$ ).

Materials and procedure The procedure was identical to that of Experiment 2, with the following exceptions. In each condition, participants were shown eight abstract and eight concrete words that were randomly drawn from a pool of 43 abstract words (e.g., merit, budget, moment, spirit, damage, season, courage, and angle) and 43 concrete words (e.g., razor, socket, window, rabbit, palace, finger, chicken, and apple) that were German translations of words previously used in a study examining the effects of word concreteness on short-term memory (Romani, McAlpine, \& Martin, 2008). Two conditions were manipulated within participants: In the survival condition, participants were required to rate how relevant the items would be for survival. In the death condition, participants were required to rate how relevant the words would be for death (see Table 1). The instructions were presented visually, and words were randomly assigned to the conditions, with the restriction that 
half of the items in each condition were abstract words and the other half were concrete. Each word was rated on a scale ranging from 1 (completely irrelevant) to 5 (very relevant).

Design A $2 \times 2$ design was used, with rating task (survival and death) and item type (concrete and abstract) as within-subjects independent variables. The dependent variables were the encoding-phase ratings and the recall performance. Given a total sample size of $N=89, \alpha=.05$, and the assumption that the average population correlation between the levels of the repeated measures factor was $\rho=.5$, an effect of size $f=0.20$ could be detected with a probability of $1-\beta=.95$.

\section{Results}

Encoding-phase ratings The relevance ratings are shown in Table 6 . The abstract words were rated as being generally more relevant for both survival and death than were the concrete words, $F(1,88)=76.82, p<.01, \eta^{2}=.47$. However, no main effect of rating task was apparent, $F(1,88)=3.05$, $p=.08, \eta^{2}=.03$, nor was an interaction between rating task and item type, $F(1,88)=3.10, p=.08, \eta^{2}=.03$.

Recall Although abstract words received higher relevance ratings than did concrete words, concrete words were remembered better than abstract words, $F(1,88)=45.44$, $p<.01, \eta^{2}=.34$ (see Fig. 3). As in the previous experiments, we found a significant survival-processing memory advantage (i.e., better recall after survival than after death ratings), $F(1,88)=5.05, p=.03, \eta^{2}=.05$. The main effect of rating task was qualified by a significant Item Type $\times$ Rating Task interaction, $F(1,88)=7.03, p<.01 \eta^{2}=.07$. Recall of the concrete words was better under survival- than under death-rating instructions, $t(88)=3.54, p<.01, \eta^{2}=.12$, but recall of the abstract words did not differ between the two conditions, $t(88)=-0.11, p=.91, \eta^{2}<.01$.

\section{Discussion}

Consistent with the observation that the survival-processing memory advantage is surprisingly robust (Kang et al., 2008;

Table 6 Mean relevance ratings as a function of rating condition and item type (Exp. 3)

\begin{tabular}{llllll}
\hline Item Type & \multicolumn{2}{l}{ Survival } & & & Death \\
\cline { 2 - 3 } \cline { 5 - 6 } & $M$ & $S D$ & & $M$ & $S D$ \\
\hline Concrete & 2.34 & 0.7 & 2.14 & 0.7 \\
Abstract & 2.89 & 0.7 & 2.88 & 0.8 \\
\hline
\end{tabular}

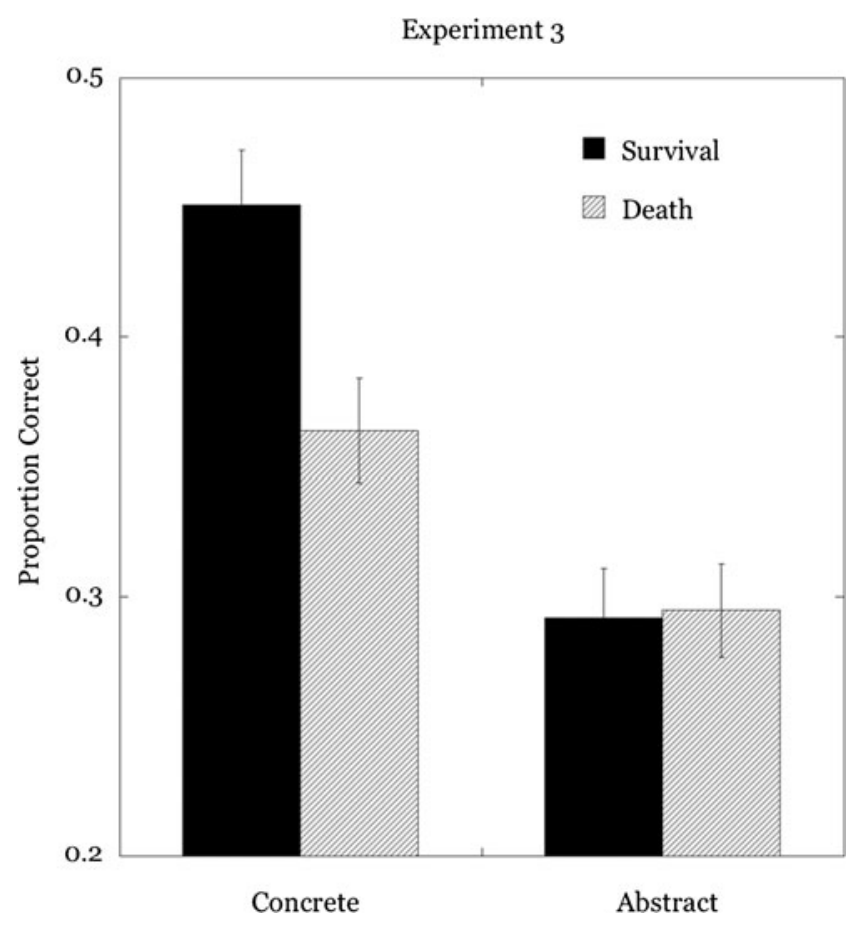

Fig. 3 Average proportions of correctly recalled words as a function of rating task (survival vs. death) and item type (concrete vs. abstract) in Experiment 3. The error bars represent the standard errors of the means

Otgaar et al., 2010; Weinstein et al., 2008) and can be obtained with different types of scenarios and rating instructions (Kostic, McFarlan, \& Cleary, 2012; Nairne, Pandeirada, Gregory, \& Van Arsdall, 2009; Röer et al., in press), a survival-processing memory advantage was obtained in Experiment 3 simply by requiring participants to think about the relevance of items for survival. Of course, it would not be legitimate to draw the conclusion that the specific details of the scenario do not affect recall, let alone against the backdrop of previous studies that have shown that subtle variations in the survival scenario can have pronounced effects on recall (Weinstein et al., 2008; but see Soderstrom \& McCabe, 2011). Nevertheless, it seems interesting that a recall advantage can be obtained by asking participants to think about the concept of survival, without using a detailed scenario (typically, the situation of being stranded in a foreign grassland characterized by predators, lack of food, and lack of potable water).

Recall was much better when participants were required to think about the relevance of words for survival than when they were required to think about the relevance of words for death. The results of a previous study led to the conclusion that thinking about one's own death prior to encoding, in comparison to thinking about a television program, led to enhanced recall (Hart \& Burns, 2012). However, just as the relationship between negativity and recall is not always a positive one, it seems questionable whether thinking about death is 
always a very effective form of encoding. On the one hand, thinking about death may mobilize cognitive resources and stimulate "deep" processing (Hart \& Burns, 2012). On the other hand, it is also possible that thinking about death might stimulate task-irrelevant thoughts that might draw cognitive resources away from the primary task. As Hart and Burns mentioned in their article, the first reaction to mortality salience usually is to suppress thoughts about death (Pyszczynski, Greenberg, \& Solomon, 1999). Therefore, inducing mortality salience before encoding might lead participants to direct their cognitive resources to an unrelated word-processing task in order to distract themselves from the death scenario. However, mortality salience probably cannot account for the memory advantage in the survivalprocessing paradigm. The results of Experiment 3 suggest that it is not thinking about one's own death that drives the survival-processing effect, but rather thinking about how to avoid death.

Interestingly, the survival-processing memory advantage was restricted to concrete words. This finding should be interpreted with caution unless it is replicated with different stimulus materials using the original grasslands survival paradigm. Nevertheless, the result fits well with the richness-of-encoding account of the survivalprocessing effect (Kroneisen \& Erdfelder, 2011), which implies that the survival-processing memory advantage is at least partly due to the fact that the survival instructions stimulate thoughts about different uses of the items that may aid survival (Röer et al., in press), which leads to increased availability of self-generated cues at retrieval in the survival condition as compared to control conditions. It is plausible to assume that concrete words stimulate thoughts about practical uses of items to a much higher degree than do abstract words. Consistent with this hypothesis, concrete words were generally remembered better than abstract words in Experiment 3. Thus, thinking about practical uses of objects that may foster survival might lead to a much stronger memory advantage than does contemplating the general relevance of abstract terms such as courage, spirit, and future for survival.

Another interesting aspect of these results is that concrete words were generally remembered better than the abstract words, although the abstract words received higher relevance ratings in both conditions. This result shows that high relevance ratings in the survival-processing paradigm do not automatically lead to better memory. This finding is consistent with several results showing that the survivalprocessing memory advantage does not depend on differences in relevance ratings between the survival condition and control conditions (Nairne \& Pandeirada, 2011; Nairne et al., 2007; Röer et al., in press). A possible interpretation of this result is that concepts such as talent, vigor, and drama appear quite relevant for both survival and death, in an abstract sense, but stimulate fewer concrete ideas than do words such as bacon, razor, or bottle, which lead to many thoughts about possible uses, thus generating many more effective retrieval cues at recall. This interpretation fits with the results of Röer et al. (in press), who found that relevance ratings could not predict the survival recall advantage. Instead, the memory advantage depended on the number of ideas that were spontaneously generated in response to each of the scenarios. In a further experiment, it was shown that congruency effects in the survival-processing paradigm could also be explained by the number of ideas generated during encoding, because more ideas are generated in response to scenario-congruent than to scenarioincongruent words. Together with the present results, these findings suggest that the relevance ratings might be much less important for predicting recall than is the number of concrete ideas stimulated by each word and scenario.

\section{General discussion}

The present study illuminates important aspects of the survival-processing effect. First, the survival-processing scenario was compared with an even more negative scenario in Experiments 1 and 2, to examine whether the survivalprocessing memory advantage can be explained by negativity and mortality salience. In Experiment 3, we examined whether thinking about survival leads to better memory than thinking about death. The implications of the results for possible proximate mechanisms of the survival-processing effect are discussed in turn.

Survival processing, negativity, and death

Given that negativity has strong effects on memory (Kensinger, 2007), it seems possible at first glance to attribute the survival memory advantage to the negativity of the scenario. However, negativity does not have positive effects on all aspects of memory. It is known that negative emotional states impair memory for many details of an encoding situation (Kensinger et al., 2007), while other aspects of memory remain unaffected by emotional valence (e.g., Kensinger \& Schacter, 2006). Therefore, it is not at all clear that negativity would enhance recall of neutral words in the survival-processing paradigm. The present results clearly show that negativity is not an important variable needed to explain the survivalprocessing advantage. From the negativity account, the prediction was derived that memory should be better after suicide ratings than after survival ratings in Experiments 1 
and 2. With respect to Experiment 3, it seems plausible that a simple negativity account would also predict that thinking about death would lead to better memory than would thinking about survival. These predictions were clearly disconfirmed by the present results, in that the survival-rating task led to a clear recall advantage over the control conditions. The suicide-rating task, by contrast, led to only a small memory advantage in comparison to the control conditions, which is consistent with the small impact of the scenario's negativity on memory.

On the basis of a recent observation that thinking about one's own death prior to encoding leads to better recall (Hart \& Burns, 2012), it has been speculated that the survivalprocessing advantage might be due to mortality salience. However, no evidence for this hypothesis could be obtained in the present experiments. The suicide-rating task used in the first two experiments directly stimulated thinking about death but was clearly less effective than the survival-rating task in promoting recall. In Experiment 3, mortality salience was induced in the most direct way, by requiring participants to think about the relevance of the words for death, which led to poorer memory performance than did requiring them to think about survival. These findings suggest that mortality salience cannot explain the survival-processing memory advantage.

It is interesting to compare the present results with those of recent studies that have obtained no advantage of the grasslands survival scenario in comparison to newly designed scenarios that could be assumed to stimulate negative emotions and mortality salience. First, Soderstrom and McCabe (2011) found that imagining protecting oneself against zombie attacks led to even better memory than did the original grassland survival scenario. Second, Kostic et al. (2012) observed good recall performance in an outerspace survival condition. The latter is very similar to the suicide scenario used in the present study, in that both describe very unusual situations, are very negative, and strongly stimulate thinking about one's own mortality, with the crucial difference that the outer-space survival scenario used by Kostic et al. required participants to focus on fitness-enhancing effects when rating the items, whereas the suicide scenario used here required participants to focus on the opposite. Thus, the results so far seem to be consistent with the assumption that rating tasks that stimulate thoughts about self-preservation and survival lead to enhanced recall, whereas rating tasks that are negative and stimulate thinking about death without a survival focus do not.

Task relevance and richness of encoding

In the first two experiments, the survival scenario led to higher relevance ratings than did the control scenarios.
However, it is known that the survival advantage is basically independent of those ratings, and no evidence has supported a strong direct effect of the ratings on recall (e.g., Kroneisen et al., in press; Nairne \& Pandeirada, 2011; Röer et al., in press). The results of Experiment 3 are consistent with those results.

According to the richness-of-encoding account, the survival-processing advantage is due to increased elaboration at encoding. More specifically, it has been suggested that the survival scenario is particularly wellsuited for stimulating many thoughts about different practical uses of items that might be helpful for survival, which may result in an increased availability of selfgenerated retrieval cues (Erdfelder \& Kroneisen, in press; Kroneisen \& Erdfelder, 2011; Kroneisen et al., in press; Röer et al., in press). The richness-of-encoding account provides a simple explanation of the finding that the recall advantage of the survival instructions over the death instructions was only found for concrete words, not for abstract words in Experiment 3. It remains for future studies to show whether the interaction with word concreteness can be replicated when comparing the original grassland survival scenario with other control scenarios.

\section{Conclusion}

To explain the survival-processing effect on memory, emotional and cognitive explanations have been discussed (Erdfelder \& Kroneisen, in press). Previous studies examining the role of emotions in the survival-processing effect have remained inconclusive. Consistent with some of these studies (Kang et al., 2008; Smeets et al., 2012), the present findings suggest that effects of (negative) emotions and mortality salience on memory cannot be considered important variables needed to explain the survival-processing memory advantage. This suggests that there is a difference between thinking about survival and thinking about death and lifethreatening situations, per se. Consistent with previous studies (Erdfelder \& Kroneisen, in press; Kroneisen \& Erdfelder, 2011; Kroneisen et al., in press; Röer et al., in press), the results of Experiment 3 suggest that thinking about possible concrete uses of items might be an important component of survival processing. Thus, the role of survival-focused elaboration should be further explored in future studies. In conclusion, the overall pattern of results is consistent with an evolutionary perspective, as well as with the richness-of-encoding account. In contrast, explanations of the survival-processing effect that are based on negative arousal or mortality salience are disconfirmed by the present results. 


\section{Appendix A}

Table 7 List of the items that were used in Experiment 2

\begin{tabular}{|c|c|c|c|}
\hline & Survival & Suicide & Irrelevant \\
\hline 1 & Zelt (Tent) & Pistole (Gun) & Attest (Attestation) \\
\hline 2 & Seil (Rope) & Rasierklinge (Razor blade) & Autogramm (Autograph) \\
\hline 3 & Decke (Blanket) & Gewehr (Rifle) & Blaupause (Blueprint) \\
\hline 4 & Topf (Pot) & Gift (Poison) & Broschüre (Brochure) \\
\hline 5 & Feuerzeug (Pocket lighter) & Schere (Scissors) & Buchumschlag (Book cover) \\
\hline 6 & Schlafsack (Sleeping bag) & Spritze (Injection) & Clownsnase (Clown nose) \\
\hline 7 & Fernglas (Binoculars) & Alkohol (Alcohol) & Drucker (Printer) \\
\hline 8 & Flasche (Bottle) & Hammer (Hammer) & Duft (Scent) \\
\hline 9 & Schaufel (Shovel) & Benzin (Fuel) & Fleck (Spot) \\
\hline 10 & Taschenlampe (Flashlight) & Dolch (Dagger) & Haar (Hair) \\
\hline 11 & Papier (Paper) & Plastiktüte (Plastic bag) & Halteverbot (Stopping restriction) \\
\hline 12 & Rucksack (Backpack) & Schraubenzieher (Screwdriver) & Hochhaus (Skyscraper) \\
\hline 13 & Streichhölzer (Matches) & Strick (Cord) & Kanzel (Pulpit) \\
\hline 14 & Hut (Hat) & Blausäure (Prussic acid) & Kissen (Pillow) \\
\hline 15 & Medikamente (Medicine) & Feuer (Fire) & Klinke (Handle) \\
\hline 16 & Plane (Canvas cover) & Glasscherbe (Broken glass) & Klotz (Brick) \\
\hline 17 & Verbandszeug (Dressing material) & Kohlenstoffmonoxid (Carbon monoxide) & Konzert (Concert) \\
\hline 18 & Eimer (Bucket) & Säge (Saw) & Kopie (Duplicate) \\
\hline 19 & Holz (Lumber) & Schlafmittel (Barbiturate) & Kunstdenkmal (Art monument) \\
\hline 20 & Hund (Dog) & Sprengstoff (Explosive) & Laus (Bug) \\
\hline 21 & Landkarte (Map) & Beil (Axe) & Neutron (Neutron) \\
\hline 22 & Löffel (Spoon) & Draht (Wire) & Plakat (Poster) \\
\hline 23 & Machete (Machete) & Eispickel (Ice pick) & Plombe (Inlay) \\
\hline 24 & Schuhe (Shoes) & Handgranate (Grenade) & Porträt (Portrait) \\
\hline 25 & Schüssel (Bowl) & Kettensäge (Chainsaw) & Prinz (Prince) \\
\hline 26 & Seife (Soap) & Nagel (Pin) & Rathaus (City hall) \\
\hline 27 & Sonnencreme (Sunscreen) & Schwert (Sword) & Ring (Ring) \\
\hline 28 & Steine (Stones) & Skalpell (Scalpel) & Rost (Rust) \\
\hline 29 & Stiefel (Boots) & Auto (Car) & Säule (Pillar) \\
\hline 30 & Stock (Stick) & Bombe (Bomb) & Schacht (Shaft) \\
\hline 31 & Trillerpfeife (Whistle) & Brieföffner (Paper knife) & Scheitel (Apex) \\
\hline 32 & Faden (Thread) & Drogen (Illegal drugs) & Schläfe (Temples) \\
\hline 33 & Gaskocher (Camping stove) & Eis (Ice) & Schlagermusik (Country music) \\
\hline 34 & Hacke (Pick) & Feuerlöscher (Fire extinguisher) & Schürze (Apron) \\
\hline 35 & Konserven (Can) & Gas (Gas) & Seifenblase (Bubble) \\
\hline 36 & Lampe (Lamp) & Guillotine (Guillotine) & Sonde (Sonde) \\
\hline 37 & Leuchtpistole (Flare gun) & Kabel (Cable) & Spruchband (Banner) \\
\hline 38 & Nähzeug (Sewing kit) & Laser (Laser) & Tango (Tango) \\
\hline 39 & Netz (Net) & Lötkolben (Soldering iron) & Tanzfläche (Dance floor) \\
\hline 40 & Pflaster (Band-aid) & Nadel (Needle) & Taste (Button) \\
\hline 41 & Salz (Salt) & Säbel (Saber) & Titel (Title) \\
\hline 42 & Schnur (Twine) & Schal (Scarf) & Tusch (Fanfare) \\
\hline 43 & Spaten (Spade) & Schnürsenkel (Shoelace) & Waagschale (Scale pan) \\
\hline 44 & Speer (Spear) & Strom (Electricity) & Wahlliste (Electoral list) \\
\hline 45 & Spiegel (Mirror) & Tabletten (Pills) & Würfel (Dice) \\
\hline
\end{tabular}




\section{References}

Allan, K., Jones, B. C., DeBruine, L. M., \& Smith, D. S. (2012). Evidence of adaptation for mate choice within women's memory. Evolution and Human Behavior, 33, 193-199.

Anderson, J. R. (1983). A spreading activation theory of memory. Journal of Verbal Learning and Verbal Behavior, 22, 261-295. doi:10.1016/S0022-5371(83)90201-3

Aslan, A., \& Bäuml, K.-H. T. (2012). Adaptive memory: Young children show enhanced retention of fitness-related information. Cognition, 122, 118-122.

Bell, R., \& Buchner, A. (2012). How adaptive is memory for cheaters? Current Directions in Psychological Science, 21, 403-408. doi: $10.1177 / 0963721412458525$

Bell, R., Buchner, A., \& Musch, J. (2010). Enhanced old-new recognition and source memory for faces of cooperators and defectors in a social-dilemma game. Cognition, 117, 261-275. doi:10.1016/ j.cognition.2010.08.020

Buchner, A., Bell, R., Mehl, B., \& Musch, J. (2009). No enhanced recognition memory, but better source memory for faces of cheaters. Evolution and Human Behavior, 30, 212-224. doi:10.1016/ j.evolhumbehav.2009.01.004

Burns, D. J., Burns, S. A., \& Hwang, A. J. (2011). Adaptive memory: Determining the proximate mechanisms responsible for the memorial advantages of survival processing. Journal of Experimental Psychology: Learning, Memory, and Cognition, 37, 206-218. doi:10.1037/a0021325

Butler, A. C., Kang, S. H. K., \& Roediger, H. L., III. (2009). Congruity effects between materials and processing tasks in the survival processing paradigm. Journal of Experimental Psychology: Learning, Memory, and Cognition, 35, 1477-1486. doi:10.1037/a0017024

Craik, F. I. M., \& Lockhart, R. S. (1972). Levels of processing: A framework for memory research. Journal of Verbal Learning and Verbal Behavior, 11, 671-684. doi:10.1016/S0022-5371(72)80001-X

Erdfelder, E., \& Kroneisen, M. (in press). Proximate cognitive mechanisms underlying the survival processing effect. In B. L. Schwartz, M. L. Howe, M. P. Toglia, \& H. Otgaar (Eds.), What is adaptive about adaptive memory? Oxford, U.K.: Oxford University Press.

Faul, F., Erdfelder, E., Lang, A.-G., \& Buchner, A. (2007). G*Power 3: A flexible statistical power analysis program for the social, behavioral, and biomedical sciences. Behavior Research Methods, 39, 175-191. doi:10.3758/BF03193146

Hart, J., \& Burns, D. J. (2012). Nothing concentrates the mind: Thoughts of death improve recall. Psychonomic Bulletin \& Review, 19, 264-269. doi:10.3758/s13423-011-0211-9

Howe, M. L., \& Derbish, M. H. (2010). On the susceptibility of adaptive memory to false memory illusions. Cognition, 115, 252-267.

Howe, M. L., \& Otgaar, H. (in press). Proximate mechanisms and the development of adaptive memory. Current Directions in Psychological Science.

Kang, S. H. K., McDermott, K. B., \& Cohen, S. M. (2008). The mnemonic advantage of processing fitness-relevant information. Memory \& Cognition, 36, 1151-1156. doi:10.3758/MC.36.6.1151

Kensinger, E. A. (2007). Negative emotion enhances memory accuracy: Behavioral and neuroimaging evidence. Current Directions in Psychological Science, 16, 213-218. doi:10.1111/ j.1467-8721.2007.00506.x

Kensinger, E. A., \& Corkin, S. (2003). Memory enhancement for emotional words: Are emotional words more vividly remembered than neutral words? Memory \& Cognition, 31, 1169-1180. doi:10.3758/BF03195800

Kensinger, E. A., Garoff-Eaton, R. J., \& Schacter, D. L. (2007). Effects of emotion on memory specificity: Memory trade-offs elicited by negative visually arousing stimuli. Journal of Memory and Language, 56, 575-591. doi:10.1016/j.jml.2006.05.004

Kensinger, E. A., \& Schacter, D. L. (2006). Amygdala activity is associated with the successful encoding of item, but not source, information for positive and negative stimuli. Journal of Neuroscience, 26, 2564-2570.

Klein, S. B., Cosmides, L., Tooby, J., \& Chance, S. (2002). Decisions and the evolution of memory: Multiple systems, multiple functions. Psychological Review, 109, 306-329.

Klein, S. B., Robertson, T. E., \& Delton, A. W. (2011). The futureorientation of memory: Planning as a key component mediating the high levels of recall found with survival processing. Memory, 19, 121-139.

Kostic, B., McFarlan, C. C., \& Cleary, A. M. (2012). Extensions of the survival advantage in memory: Examining the role of ancestral context and implied social isolation. Journal of Experimental Psychology: Learning, Memory, and Cognition, 38, 1091-1098. doi:10.1037/a0026974

Kroneisen, M., \& Erdfelder, E. (2011). On the plasticity of the survival processing effect. Journal of Experimental Psychology: Learning, Memory, and Cognition, 37, 1553-1562.

Kroneisen, M., Erdfelder, E., \& Buchner, A. (in press). The proximate memory mechanism underlying the survival-processing effect: Richness of encoding or interactive imagery? Memory. doi:10.1080/09658211.2012.741603

Levine, L. J., \& Edelstein, R. S. (2009). Emotion and memory narrowing: A review and goal-relevance approach. Cognition and Emotion, 23, 833-875.

Mather, M. (2007). Emotional arousal and memory binding: An objectbased framework. Perspectives on Psychological Science, 2, 3352. doi:10.1111/j.1745-6916.2007.00028.x

Nairne, J. S. (2010). Adaptive memory: Evolutionary constraints on remembering. In B. H. Ross (Ed.), The psychology of learning and motivation: Advances in research and theory (Vol. 53, pp. 132). San Diego, CA: Elsevier Academic Press.

Nairne, J. S., \& Pandeirada, J. N. S. (2008a). Adaptive memory: Is survival processing special? Journal of Memory and Language, 59, 377-385. doi:10.1016/j.jml.2008.06.001

Nairne, J. S., \& Pandeirada, J. N. S. (2008b). Adaptive memory: Remembering with a stone-age brain. Current Directions in Psychological Science, 17, 239-243. doi:10.1111/j.1467-8721.2008.00582.x

Nairne, J. S., \& Pandeirada, J. N. S. (2010). Adaptive memory: Nature's criterion and the functionalist agenda. The American Journal of Psychology, 123, 381-390. doi:10.5406/amerjpsyc.123.4.0381

Nairne, J. S., \& Pandeirada, J. N. S. (2011). Congruity effects in the survival processing paradigm. Journal of Experimental Psychology: Learning, Memory, and Cognition, 37, 539-549. doi:10.1037/a0021960

Nairne, J. S., Pandeirada, J. N. S., Gregory, K. J., \& Van Arsdall, J. E. (2009). Adaptive memory: Fitness relevance and the hunter-gatherer mind. Psychological Science, 20, 740-746. doi:10.1111/j.1467-9280.2009.02356.x

Nairne, J. S., Pandeirada, J. N. S., \& Thompson, S. R. (2008). Adaptive memory: The comparative value of survival processing. Psychological Science, 19, 176-180. doi:10.1111/j.1467-9280.2008.02064.x

Nairne, J. S., Thompson, S. R., \& Pandeirada, J. N. S. (2007). Adaptive memory: Survival processing enhances retention. Journal of Experimental Psychology: Learning, Memory, and Cognition, 33, 263-273. doi:10.1037/0278-7393.33.2.263

New, J., Krasnow, M. M., Truxaw, D., \& Gaulin, S. J. C. (2007). Spatial adaptations for plant foraging: Women excel and calories count. Proceedings of the Royal Society B, 274, 2679-2684.

Otgaar, H., \& Smeets, T. (2010). Adaptive memory: Survival processing increases both true and false memory in adults and children. Journal of Experimental Psychology: Learning, Memory, and Cognition, 36, 1010-1016. doi:10.1037/a0019402 
Otgaar, H., Smeets, T., \& van Bergen, S. (2010). Picturing survival memories: Enhanced memory after fitness-relevant processing occurs for verbal and visual stimuli. Memory \& Cognition, 38, 23-28. doi:10.3758/MC.38.1.23

Pyszczynski, T., Greenberg, J., \& Solomon, S. (1999). A dual-process model of defense against conscious and unconscious death-related thoughts: an extension of terror management theory. Psychological Review, 106, 835-845.

Röer, J. P., Bell, R., \& Buchner, A. (in press). Is the survivalprocessing memory advantage due to richness of encoding? Journal of Experimental Psychology: Learning, Memory, and Cognition. doi:10.1037/a0031214

Röer, J. P., Bell, R., Dentale, S., \& Buchner, A. (2011). The role of habituation and attentional orienting in the disruption of shortterm memory performance. Memory \& Cognition, 39, 839-850. doi:10.3758/s13421-010-0070-z
Romani, C., McAlpine, S., \& Martin, R. C. (2008). Concreteness effects in different tasks: Implications for models of short-term memory. Quarterly Journal of Experimental Psychology, 61, 292-323.

Smeets, T., Otgaar, H., Raymaekers, L., Peters, M. J. V., \& Merckelbach, H. (2012). Survival processing in times of stress. Psychonomic Bulletin \& Review, 19, 113-118. doi:10.3758/s13423-011-0180-Z

Soderstrom, N. C., \& McCabe, D. P. (2011). Are survival processing memory advantages based on ancestral priorities? Psychonomic Bulletin \& Review, 18, 564-569. doi:10.3758/s13423-011-0060-6

Weinstein, Y., Bugg, J. M., \& Roediger, H. L., III. (2008). Can the survival recall advantage be explained by basic memory process? Memory \& Cognition, 36, 913-919. doi:10.3758/MC.36.5.913

Wilson, S., Darling, S., \& Sykes, J. (2011). Adaptive memory: Fitness relevant stimuli show a memory advantage in a game of pelmanism. Psychonomic Bulletin \& Review, 18, 781-786. 